\title{
A Summary of the Study on the Authenticity of Traditional Village Architecture Space
}

\author{
Fangzhou Mi, Yu Wang \\ Urban and Rural Planning, School of Civil Engineering and Architecture, Southwest University of Science and Technology, \\ Mianyang, China \\ Email:361749052@qq.com, mifangzhou2013@163.com
}

How to cite this paper: Mi, F. Z., \& Wang, Y. (2021). A Summary of the Study on the Authenticity of Traditional Village Architecture Space. Open Journal of Social Sciences, 9, 228-240.

https://doi.org/10.4236/jss.2021.96018

Received: May 11, 2021

Accepted: June 21, 2021

Published: June 24, 2021

Copyright (c) 2021 by author(s) and Scientific Research Publishing Inc. This work is licensed under the Creative Commons Attribution International License (CC BY 4.0).

http://creativecommons.org/licenses/by/4.0/

\begin{abstract}
The principle of authenticity is the basic and primary principle of the protection of historical and cultural heritage. It is the key to measuring the value of the heritage and the basis for the protection of the heritage. It is inseparable from the protection of traditional villages. As an important part of the cultural heritage of traditional villages, architectural space is an important carrier of traditional village memory and culture, carrying various material and intangible functions. At present, the importance of historical and cultural heritage protection and authenticity protection of traditional villages is becoming more and more prominent. This article summarizes relevant domestic and foreign research, hoping to understand the authenticity protection of historical and cultural heritage and traditional village architectural space from existing research results.
\end{abstract}

\section{Keywords}

Traditional Villages, Historical and Cultural Heritage Protection, Authenticity

\section{Research Background}

\subsection{The Importance of Authenticity Research}

The principle of authenticity is the basic and primary principle of the protection of historical and cultural heritage, and is the key to the standard for measuring the value of the heritage and the basis for the protection of the heritage. With the progress of society and the needs of urban development, the historical heritage and cultural relics of many cities and towns have been destroyed in the course of economic development and development. Aware of the urgency of the problem, the protection of cultural relics, history, and traditional buildings has become an important strategic component of urban and rural development, and has been 
widely used in the fields of architecture, urban planning, landscape architecture, heritage protection, etc. Destroying the authenticity of historical heritage will lead to the disappearance of important historical information, and the lack of awareness of authenticity and lack of protection awareness will also hinder the protection of historical and cultural heritage.

First of all, at the material level, on the one hand, the protection and repair behavior damages the authenticity, such as the failure to restore the original structure of the historical building in the structural repair, or the material selection is quite different from the original material of the historical building. Functionally change the original functional purpose and so on. On the other hand, the unfavorable supervision of the government and the protection subject and the weak protection awareness make the authenticity of cultural relics lost in the development process.

Secondly, at the non-material level, the lack of authenticity protection for culture and perception will result in the loss of the subject of cultural authenticity, the dislocation of cultural display in time and space, the lack of cultural integrity, and the simplification of cultural diversity. In addition, the neglect and misunderstanding of the cultural subject have caused the cultural subject to lose the dominant power, leading to the destruction of the authenticity of administrative power and commercial operations, and the forcible transplantation and grafting of cultural symbols have caused great damage to the intangible authenticity.

The third is at the environmental level on which history depends. Many laws and regulations for the protection of historical culture have only made requirements and instructions for the authenticity protection of historical buildings, historical features, and traditional patterns. This has led to a lack of protection in many protection practices. The historical space environment, surrounding residents, and natural environment considerations on which historical heritage relies have led to the destruction of the surrounding environment of cultural relics and historic sites. For example, the construction of private houses, commercial shops and other buildings around historical sites destroys the original historical environment and spatial pattern, and makes the original distinctive space lose its authenticity.

\subsection{The Necessity of Authenticity Protection and Development in Traditional Villages}

As an important part of Chinese historical and cultural heritage, traditional villages are also inseparable from authenticity. Traditional villages have rich historical and cultural values. The villages and villagers basically follow the traditional patterns, traditional styles, traditional shapes, traditional materials, traditional techniques, traditional spatial scales and the original ecological dependent environment that have been inherited from the ancestors, maintaining the traditional living and living forms and Farming culture has distinctive national and regional cultural characteristics. In the process of protecting and developing vil- 
lages, these special historical and cultural information must be preserved, otherwise the basis for their existence will be lost.

With the acceleration of social development, urbanization and global tourism, the authenticity and culture of many traditional villages are facing unprecedented challenges and impacts. First of all, since the protection of authenticity is not paid attention to, there are many over-exploitation, unreasonable, and blind plastic transformations in the development process, which to a large extent destroys the authenticity of traditional villages. In the process of seeking the development of traditional villages, many traditional villages promote the development of the village economy through the development of tourism. In order to strengthen the spatial image of traditional villages and unified planning to create the village image, many villages have abandoned their own historical and cultural characteristics, causing the same pattern in the ancient villages and "one side of a thousand villages" destroys the authentic elements of traditional villages and the natural ecological environment at will. Secondly, with the development of society, farmers' incomes and lifestyles are changing. Traditional buildings with a lack of infrastructure and poor internal environment can no longer meet the living requirements of modern people. Improving living conditions has become an urgent desire for many aborigines. However, because the original historical buildings, traditional buildings or historical environment are too dilapidated, it is difficult to repair and improve. In addition, even in order to relieve the pressure on the construction of ancient villages, many traditional villages have "demolished the old and built the new" phenomenon, causing a large number of historical buildings to be destroyed and the traditional style of the village to be fragmented. Third, the protection subject's lack of a correct understanding of authenticity has also led to the destruction of the original historical information of the object during the renovation and transformation of ancient buildings, making the authenticity disappear.

\subsection{The Main Problems Currently Facing the Architectural Space of Traditional Villages}

As an important part of the cultural heritage of traditional villages, architectural space is an important carrier of traditional village memory and culture, carrying various material and intangible functions. In the process of continuous development and evolution of traditional villages, villagers' life patterns will change with changes in the external environment and internal relations. This change in life patterns has also led to the demise of certain architectural functions in the village, which makes the architectural space lose the meaning of existence. As a result, several phenomena have appeared in the village. One phenomenon is that although many architectural spaces still exist during the evolution of the village, they have been neglected and abandoned due to the disappearance of their use functions. Another phenomenon is that when the architectural space is being transformed and demolished, the original form of the architectural space is destroyed, resulting in the loss of authenticity. Both of these pheno- 
mena have caused waste and destruction to the historical heritage resources of the village.

\section{Research Purposes}

Based on the principle of authenticity, this research will be based on the architectural space of traditional villages. From the space carrying level of architectural functions, it proposes different types of architectural space restoration and renewal strategies, so as to solve the current use of architectural space by villagers in traditional villages. The differences and contradictions between the appeal and the historical authenticity of the space site make the two organically unified.

The purpose of the research is to solve the two problems of traditional village architectural space:

1) Make the architectural space of the traditional village meet the actual function, adapt to the modern lifestyle, and be convenient for the villagers to use, and carry out the functional transformation and update of the site function.

2) To make the architectural space of the traditional village is protected, the space cultural heritage is continued, and its original characteristics are preserved.

\section{Significance of Research}

At present, the protection and development of traditional villages are facing the dual pressure of urgency and necessity. It is necessary to protect the historical and cultural imprints of traditional villages and to meet the functions and requirements of the modern development of the villages. At the same time, the protection and renewal of the historical and cultural relics of traditional villages cannot be separated from the original research and analysis. The original traditional village renewal model is difficult to solve the current problems. It is urgent to propose a new guiding principle, systematic evaluation standard and implementation system. Through this research, many current scholars' cognition of "authenticity" is analyzed and expanded, and the originality connotation in line with the current traditional village architectural space is proposed, and the originality is improved and supplemented in the restoration and renewal of the traditional village architectural space level. The scope of application provides reference and practical significance for the protection and development of current traditional villages, so as to better preserve and use the historical and cultural heritage of traditional villages.

\section{Research Status and Development Trend}

\subsection{International Research Status and Trends}

The international discussion on the concept of "authenticity" has made continuous progress and development, and a relatively mature cognitive system and framework has gradually formed, which is mainly reflected in a series of important international charters related to authenticity. In academic research, the au- 
thenticity research mostly revolves around the protection and restoration of historical cultural monuments, heritage tourism development, etc., involving multiple disciplines. According to the SCI literature journal search, there are about 81,581 documents as of 2020, including computer science, Sociology, pedagogy, philosophy and other disciplines, based on research results that are similar to the term "authenticity" defined in the Venice Charter, are used for historical heritage protection research, mainly in sociology (accounting for $9.21 \%$ ), environmental science (0.84\%), engineering (6.39\%) and economics (3.13\%), this type of research is more biased towards the theories and methods of historical heritage protection and tourism development. There is also the computer science level (accounting for 14.54\%) on "authenticity" research is more through computer applications, digital modeling, information system establishment methods, focusing on specific areas of operation, this type of research is more technical and practical (shown in Table 1).

Table 1. The research on authenticity, historical villages and architecture space.

\begin{tabular}{lll}
\hline Research Content & Object
\end{tabular}

\section{The research on Authenticity}

Cultivate locality and individuality through authenticity, constitute an important place for blending and reformulating tradition and modernity, and create heritage and tourism to rejuvenate the economy (AlSayyad \& Nam, 2014)

intangible

Milena Ivanovic took the Constitution Hill in Johannesburg, South Africa as an example, studied the perceptual authenticity of iconic heritage in urban tourism, and evaluated the authentic experience of iconic places (Ivanovic, 2014)

Physical entity and space

Through interdisciplinary multi-spectral modeling to protect historical sites, the Church of the Holy Sepulchre will be restored, using digital heritage and image processing methods to propose the importance of sustainable preservation of the structure and the authenticity of the building (Moropoulou, 2018)

Exploit and reuse the potential of New Zealand's historical architectural heritage based on authenticity, minimize demolition and reuse of buildings, preserve heritage structure, maintain authenticity and highlight cultural heritage (Howse \& Jadresin-Milic, 2019)

Use the evaluation criteria of the principle of authenticity to evaluate the historical heritage of 7 countries in Tunisia (Ben Said \& Kharrat, 2019)

Study the brand experience and the structural relationship between authenticity and place attachment in slow travel destinations (Shang, 2020)

Discusses the balance between tourism and urban renewal, as well as the authenticity of the relationship and the reconstructed cultural relic space $(\mathrm{Su}, 2020)$

Study the influence of traditional costume experience on the authenticity of cultural heritage festivals and festival satisfaction (Lee, 2020)

\section{The research on historical villages}

Through cooperation between local communities in Aga Village in Bali and tourism entrepreneurs, to develop creative tourism and maintain harmony in traditional social and cultural life (Hanan, 2017)

By analyzing the traditional pattern of characteristic traditional houses, the plane and elevation characteristics of traditional houses, construction technology and building materials, the reasons for the decline of the village and the protection issues are studied and protection suggestions are made for this (Acar Bilgin, 2019)

The disaster risk and countermeasures of the impact of modernization on historical mountain villages were studied (Li, Hasemi, \& Nozoe, 2020)

Researched the role of the social and cultural methods of tourist villages in community life, and explored the protection of the cultural heritage of local traditional houses as tourism assets (Rudwiarti, Pudianti, \& Hadi, 2019)
Physical entity

Physical entity

Physical entity intangible and Space

Physical entity and space

intangible

intangible

Physical entity

Physical entity

intangible 


\section{The research on architecture space}

The reuse of historical buildings in the metropolitan area of Turin, Italy. Use the multi-attribute value theory (MAVT) method to evaluate the sustainability of cultural heritage projects (Ferretti, Bottero, \& Physical entity Mondini, 2013)

Taking the Alexandria National Museum as an example, the compatibility of new uses of heritage buildings was evaluated (Elsorady, 2014)

Physical entity

Interior space

Research on the spatial physical properties of historic buildings and integrate the use of energy efficiency and renewable energy (Cabeza, Gracia, \& Pisello, 2018)

Using circular economy strategies to study the adaptive reuse of cultural heritage buildings to reduce the impact on the environment (Foster, 2019)

Physical entity

In "Communication and Space", outdoor activities are divided into three categories: necessary activities, spontaneous activities, and social activities. The focus is on the analysis and discussion of the conditions for spontaneous activities and social activities to occur. Suggestions for space design

Intangible and space

Outside space (Gehl, 1971)

The urban image theory proposes that the exterior space of the building is located at the junction of the building and the city, and is connected with the building and the city. The urban space should be recognizable, structural and imageable (Lynch, 1960)

Physical entity and intangible

At the research level of historical villages, there is no definition of "traditional villages" abroad, and foreign scholars often permeate them into rural tourism and the renewal of historical villages for the study of historical small towns and historical buildings. In the discussion of the internal space function of the building, the main focus is on the function, material, and physical properties of the building itself, while the external space focuses on the study of non-material forms.

\subsection{Chinese Research Status and Development Trend}

The "unchanging the original state of cultural relics", which has been followed for a long time in the protection of cultural relics and historical sites in China, has a similar meaning to authenticity. The domestic research on authenticity began in the late 1990s, first on the basis of the fields of history, society, and archaeology, followed by the continuous integration of academic achievements in the fields of planning, architecture, and geography, and then obtained through a series of legal documents. Extension. The main content of authenticity research focuses on three aspects: tourism development, heritage protection and renewal strategies.

The research on traditional villages began to develop gradually in the 1950s, and Professor Ruan Yisan initiated the research on the protection of traditional villages and towns in China. Since the early 1990s, scholars in the field of architecture have also begun to pay attention to the protection of traditional villages in terms of vernacular architecture and settlement landscape. Chen Zhihua has carried out investigations and researches on the vernacular architecture of ancient villages, and Peng Yigang has conducted research on traditional village landscapes. Later, scholars in other fields such as geography also carried out a 
series of research work on historical and cultural villages and towns. In 2012, the Ministry of Housing and Urban-Rural Development of my country promulgated the "Guiding Opinions on Strengthening the Protection and Development of Traditional Villages", which clarified the importance and necessity of the protection and development of traditional villages, conducted surveys on traditional villages, established a directory system, and promoted the protection and development of traditional villages. Preparation and implementation (shown in the Table 2).

Table 2. The research on authenticity, architecture space of historical villages.

Research Content Object

\section{The research on Authenticity}

Based on the authenticity perspective, the historical town renewal implementation strategy and guarantee mechanism are studied, the strategy for the renewal of the ancient town is proposed, the authenticity content is determined, and the space classification and development model are carried out (Xu, 2018).

Research based on the authenticity of contemporary exhibition architectural form creation, construct architectural forms that respond to environmental characteristics, and create space places that pay attention to situational experience (Tian, 2019).

From the perspective of authenticity, research on the protection and repair technology of the former site of the Puppet Manchukuo Synthetic Law Office, and formulate strategies for overall control and "background and context", "function and use" and the authenticity of the building itself (Yue, 2019).

Research on the authenticity of wide and narrow alleys based on the streets and courtyards of Chengdu Shaocheng, and propose protection strategies (Zhang, 2019a).

Research on the authenticity of the Central Plains in the renewal of historical blocks, extract and analyze the style and design elements, summarize the protection of the material form, and inherit the historical context. It focuses on the construction of authenticity from the perspectives of architectural form, block texture, street interface, aboriginal inhabitants, and cultural features (Wang, 2020).

The research on architecture space

Regarding the protection and utilization of historical buildings, the development and utilization of industrial heritage buildings, and the reuse of buildings in Hangzhou, from the perspective of the concept of adaptive function renewal of old buildings, establish a planning and management strategy for the adaptive function renewal of old buildings (Li, 2012).

Through the organic renewal of the architectural space of the village in the city, the memory of the folk culture can be preserved (Zhu, 2013).

Physical entity

Physical entity and space

Physical entity

Physical entity and space

Physical entity and intangible and space

Physical entity

For different types of vernacular architectural heritage, research its protection and utilization modes, and implement specific measures for the protection and utilization of vernacular architectural heritage, and carry out innovative functional updates of ordinary enclosures other than cultural preservation units (Shi, 2015).

General building space
Use the principle of symbiosis on the mechanism of interaction between historical buildings and other related factors to construct a symbiosis design strategy system for the regeneration of historical buildings (Wan, 2017).

Starting from the theory of urban renewal and old building renovation, the function conversion of old buildings is studied, and the old building function conversion decision-making index system is constructed from the aspects of historical culture, building ontology, regional environment, social benefits, and economic benefits. Established the evaluation method of function conversion (Lin, 2015).

According to the theoretical research on the function conversion of old buildings, the concept of the function conversion transformation of commercial buildings is discriminated, and it is proposed that the internal and external spaces of the original commercial buildings need to be renovated, transformed and reused with the transformation of the use of space (Zhao, 2019b).
Physical entity

Physical entity

Physical entity

Physical entity

Physical entity 
Architectural space in a traditional village
From the prominent contradiction between the residents' lifestyle and the traditional residential environment, and the current situation of the room being idle due to the damage and obsolescence of the building, it proposes the renewal development strategy of the spatial form from the aspects of functional layout, indoor environment, spatial reorganization and functional replacement, and building components (Che, 2015).

Research on the design strategy for the renovation of homestays for the protection and utilization of traditional houses in the village, from the perspectives of spatial function replacement, restoration and renovation of various parts of the building, optimization of building structure, adaptive renovation, vernacular architectural design and experience of vernacular elements, etc. (Wang, 2017a).

Based on the public space of traditional ethnic minority villages in Guangxi, explore the internal order and logic of the village public space form, regional environment, and ethnic culture (Wei, 2017).

Update through the analysis of the types of public buildings in traditional villages in Hunan (Wu, 2018).

Research on the inheritance and renewal of traditional villages and architectural spaces in Guangxi. It is believed that space is the basic carrier of the interaction between environment, settlements, buildings and people. The spatial pattern, spatial elements, spatial structure and internal and external spaces of buildings are classified and compared (Pan, 2018).

Research on the spatial form and protection and utilization of traditional village buildings in Gantang Village, based on spatial morphology (Zhao, 2019b). Li Wenda proposes protection methods and principles based on the spatial characteristics of traditional village temple buildings (He, 2019).

Originally from the regional and dynamic perspective, the cultural connotation carried by the space, researched the problem of focusing on architectural forms and neglecting cultural connotations in the protection and renewal of traditional villages ( $\mathrm{Li}, 2019)$.

Based on the renewal of buildings and spaces, the principles and spatial levels of the renewal and utilization of traditional villages in the suburbs of Beijing are proposed, which provides a theoretical method for the reutilization of buildings (Zhao, 2019a).

Determined the necessity of the existence and reuse of traditional public buildings and spaces, and studied the feasibility and value of reuse of architectural space (Zhang, 2019b).
Physical entity and intangible intangible

Physical entity

intangible

Intangible and space

Intangible and space

Physical entity and space

Physical entity

\section{Conclusion and Outlook}

\subsection{Summary of Research Status}

After comprehensively analyzing the research status and trends of "authenticity", "traditional village" and "architectural space" at home and abroad, the summary is as follows:

First, the research on authenticity is mainly concentrated in the field of historical and cultural heritage, and its concept has been developing and expanding, and the level of application has become more and more extensive, from the original meaning of authenticity as a religious relic in the early days to the application in the field of heritage protection. It is mainly used to define, evaluate and monitor a basic factor of cultural heritage. In general, the connotation of authenticity is no longer limited to its original meaning. In addition to authentically reproducing the original appearance of the cultural heritage, it also includes cultural diversity, the place and environment where the heritage exists, and so on. Its manifestation gradually extends from the material level to the non-material cultural level and the spatial level. Western scholars put more emphasis on the combination of historical heritage, tourism and management in the application 
of the principle of authenticity. Chinese scholars have used authenticity in the protection of traditional villages in the application of authenticity in recent years. Although the principle of authenticity is widely used in the protection and repair of the material level, few scholars have conducted research on the authenticity of architectural spaces.

Second, at the research level of traditional villages, although the main content of Chinese research is many, it mainly focuses on culture, tourism development, traditional village value, spatial form, public space and traditional village protection and development. Research on traditional villages is valuable. The study of its characteristics, from the perspective of the village's historical culture and its own characteristics, form and evolution, analyzes its village's characteristics and historical, cultural, artistic, scientific, and social values. It was not until 2016 that scholars connected authenticity with traditional villages (Zhu \& Yang, 2016). For example, some scholars formulated a list of authenticity elements for the architectural style of traditional villages (Xiao, 2016), and proposed the composition of authenticity from the physical carrier level of traditional villages. Elements (Xiong, 2017), summarize the authenticity elements from the artificial, landscape and natural environment elements of traditional villages (Wang, 2018), and summarize the obstacles to heritage authenticity protection (Pan, 2017) based on the theory of authenticity, make traditional village archives formulation, planning and publicity operation (Wang, 2017b). Therefore, the research on the application of authenticity in traditional villages needs to be further expanded.

Third, at the architectural space level, Western scholars have rich theoretical results on the interior and exterior of the general architectural space. However, in the restoration and renewal of the architectural space of historical buildings and rural historical heritage, more research focuses on the repair and renewal of the function, material, and physical properties of the building itself, but lack of the authentic connection of the external space of the building and the study of the spiritual function of carrying intangible culture. Chinese scholars have focused more on the study of spatial form, landscape influence and physical entities of buildings in the architectural space of traditional villages, but lacked the repair and update of architectural space functions.

Therefore, it is necessary to link the principle of authenticity with traditional villages and architectural space, and establish the application of the principle of authenticity at the architectural space level of traditional villages. It is necessary to settle on the functional level of architectural space.

\subsection{Problems to Be Solved}

Through the literature review of this article, a certain foundation has been laid for the follow-up research. In the study of the architectural space of traditional villages, we can establish an evaluation system based on the principle of authenticity and architectural space influence factors, give different strategies for dif- 
ferent architectural space types and existing problems in traditional villages, and propose the traditional village architectural space. Repair and update mode.

\subsection{Research Significance}

Through a literature review of important concepts such as "authenticity", "traditional villages" and "architectural space" and related theories, this paper analyzes the current application scope of "authenticity" and finds research gaps. In the follow-up research, the system construction of authenticity and traditional village building space restoration and renewal will be further proposed, and combined with the actual cases of traditional villages for application and practice. By summarizing the necessity of restoration and renewal of traditional village buildings, the concept of "authenticity" is introduced.

1) Analyze the current understanding of "authenticity" and propose a new evaluation system for the restoration and renewal of traditional village architectural spaces.

2) Establish an authentic implementation path in the restoration and renewal of traditional village buildings.

3) Through case practice and theoretical application, the feasibility of the authenticity evaluation system for the restoration and renewal of traditional village buildings is demonstrated.

\section{Conflicts of Interest}

The authors declare no conflicts of interest regarding the publication of this paper.

\section{References}

Acar Bilgin, E. (2019). Rural Architectural Characteristics and Conservation Issues of Alaaddinbey Village in Bursa, Turkey. In D. Hawkes et al. (Eds.), Conservation of Architectural Heritage. Advances in Science, Technology \& Innovation (IEREK Interdisciplinary Series for Sustainable Development) (pp. 161-178). Cham: Springer. https://doi.org/10.1007/978-3-030-10871-7 14

AlSayyad, N., \& Nam, S. (2014). Authenticity and the Manufacture of Heritage. In C. Smith (Ed.), Encyclopedia of Global Archaeology (pp. 22-24). New York: Springer. https://doi.org/10.1007/978-1-4419-0465-2 376

Ben Said, I., \& Kharrat, F. (2019). Degree of Respect for Authenticity in the House's Restorations of the Medina of Tunis. In D. Hawkes et al. (Eds.), Conservation of Architectural Heritage. Advances in Science, Technology \& Innovation (IEREK Interdisciplinary Series for Sustainable Development) (pp. 221-241). Cham: Springer. https://doi.org/10.1007/978-3-030-10871-7_18

Cabeza, L. F., de Gracia, A., \& Pisello, A. L. (2018). Integration of Renewable Technologies in Historical and Heritage Buildings: A Review. Energy and Buildings, 177, 96-111. https://doi.org/10.1016/j.enbuild.2018.07.058

Che, X. M. (2015). Research on the Renewal of the Internal Space form of Huizhou Traditional Residential Buildings. Xi'an: Xi'an University of Architecture and Technology.

Elsorady, D. A. (2014). Assessment of the Compatibility of New Uses for Heritage Buildings: The Example of Alexandria National Museum, Alexandria, Egypt. Journal of 
Cultural Heritage, 15, 511-521. https://doi.org/10.1016/j.culher.2013.10.011

Ferretti, V., Bottero, M., \& Mondini, G. (2013). Decision Making and Cultural Heritage: An Application of the Multi-Attribute Value Theory for the Reuse of Historical Buildings. Journal of Cultural Heritage, 15, 644-655. https://doi.org/10.1016/j.culher.2013.12.007

Foster, G. (2019). Circular Economy Strategies for Adaptive Reuse of Cultural Heritage Buildings to Reduce Environmental Impacts. Resources, Conservation and Recycling, 152, 104507. https://doi.org/10.1016/j.resconrec.2019.104507

Gehl, J. (1971). Livet mellem husene, udeaktiviteter og udemiljøer.

Hanan, H. (2017). Stay, Play, and Learn at Bali Aga Traditional Village. In C. Silver, L. Marques, H. Hanan, \& I. Widiastuti (Eds.), Proceedings of the 6th International Conference of Arte-Polis (pp. 139-148). Singapore: Springer. https://doi.org/10.1007/978-981-10-5481-5 14

He, W. Q. (2019). Research on the Spatial Form and Protection and Utilization of Traditional Village Architecture in Shanggantang Village, Jiangyong County, Xiangnan. Zhengzhou: Zhongyuan Institute of Technology.

Howse, W., \& Jadresin-Milic, R. (2019). Functional Heritage. Reconnecting with the Iron Web. In G. Amoruso, \& R. Salerno (Eds.), Cultural Landscape in Practice. Lecture Notes in Civil Engineering, Vol 26 (pp. 271-295). Cham: Springer. https://doi.org/10.1007/978-3-030-11422-0_19

Ivanovic, M. (2014). The Perceived Authenticity of Iconic Heritage Sites in Urban Tourism: The Case of Constitutional Hill, Johannesburg, South Africa. Urban Forum, 25, 501-515. https://doi.org/10.1007/s12132-014-9241-5

Lee, K. (2020). The Influence of Traditional Costume Experience on Cultural Heritage Festivals. International Journal of Tourism and Hospitality Research, 34, 37-51.

Li, C. J. (2012). Research on the Management Strategy of the Function Renewal of Old Buildings in Hangzhou. Hangzhou: Zhejiang University.

Li, M., Hasemi, Y., \& Nozoe, Y. (2020). Study on Disaster Risks and Countermeasures Influenced by the Impact of the Modernization Process in Historical Mountain Villages: A Case Study of Hanazawa Historical Village, Japan. International Journal of Disaster Risk Reduction, 41, 101290. https://doi.org/10.1016/j.ijdrr.2019.101290

Li, X. (2019). The Cultural Refraction and Expression of the Architectural Space of Traditional Villages-Take the traditional villages around Lijiang Scenic Area as an Example. Journal of Guilin University of Technology, 39, 82-93.

Lin, H. Y. (2015). Research on Decision-Making of Function Conversion of Old Buildings in Urban Renewal. Chongqing: Chongqing University.

Lynch, K. (1960). The Image of the City. Cambridge: The MIT Press.

Moropoulou, A. (2018). Transdisciplinary Multispectral Modeling and Cooperation for the Preservation of Cultural Heritage. First International Conference, TMM_CH 2018, Athens, 10-13 October 2018, Revised Selected Papers, Part II. https://doi.org/10.1007/978-3-030-12960-6

Pan, L. (2018). Research on Inheritance and Renewal of Traditional Villages and Architectural Space in Guangxi. Chongqing: Chongqing University.

Pan, X. (2017). The Protection of the Authenticity of the Heritage of the Traditional Villages in Southern Anhui from the Perspective of Geomantic Omen. Wuhan: Central China Normal University.

Rudwiarti, L. A., Pudianti, A., \& Hadi, P. (2019). Sociocultural Capital and Its Roles in 
Traditional Heritage Housing Conservation Scheme: A Case Study of Brayut Tourism Village (Yogyakarta, Indonesia). In U. Stankov, S. N. Boemi, S. Attia, S. Kostopoulou, \& N. Mohareb (Eds.), Cultural Sustainable Tourism. Advances in Science, Technology \& Innovation (IEREK Interdisciplinary Series for Sustainable Development) (pp. 131-137). Cham: Springer. https://doi.org/10.1007/978-3-030-10804-5 13

Shang, W. W. (2020). Sustainability, Volume: Issue 12: Document Number: 2784.

Shi, Y. Y. (2015). Research on Multi-dimensional Protection and Utilization of Vernacular Architecture Heritage Based on Functional Renewal. Nanchang: Nanchang University.

Su, X. Y. (2020). Sustainability. Volume: Issue 12: Document Number: 5830.

Tian, H. M. (2019). Research on the Creation of Contemporary Exhibition Architectural form Based on Authenticity. Harbin: Harbin Institute of Technology.

Wan, F. D. (2017). Research on the Regeneration of Urban Historical Buildings Based on the Concept of Symbiosis. Guangzhou: South China University of Technology.

Wang, C. T. (2018). Research on the Authenticity Protection and Development of the Ancient Miao Village in Dayuan, Suining, Shaoyang. Changsha: Hunan University.

Wang, C. Y. (2020). Reflections on the Authenticity of the Central Plains in the Renewal of Historical Blocks-Taking Dalian Dongguan Street as an Example. Urban Architecture, $17,128-129$.

Wang, Y. N. (2017a). Research on the Design Strategy of Homestay Renovation Based on the Protection and Utilization of Traditional Village Houses. Chongqing: Chongqing University.

Wang, Z. (2017b). Analysis of the Authenticity in the Protection and Development of the Traditional Village of Luotian Wushiyan Embankment. Tianjin: Tianjin University.

Wei, Y. C. (2017). Research on the Public Space Forms of Guangxi Ethnic Minority Traditional Villages. Guangzhou: South China University of Technology.

Wu, H. Z. (2018). Research on the Type Analysis and Function Renewal of Public Buildings in Hunan Traditional Villages. Changsha: Hunan University.

Xiao, Y. P. (2016). Research on the Authenticity Protection of Traditional Villages. Xiangtan: Hunan University of Science and Technology.

Xiong, Q. (2017). Research on the Authenticity Protection of the Traditional Villages of Paiyao in Liannan. Guangzhou: South China University of Technology.

$\mathrm{Xu}, \mathrm{W}$. (2018). Research on the Implementation Strategy and Guarantee Mechanism of Historical Town Renewal Based on the Perspective of Authenticity. Hangzhou: Zhejiang University.

Yue, Z. Y. (2019). Research on the Protection and Repair Technology of the Puppet Manchukuo's Synthetic Legislation Site from the Perspective of Authenticity. Changchun: Jilin Architecture University.

Zhang, H. Y. (2019a). Study on the Authenticity of Kuanzhai Alleys Based on the Streets and Courtyards of Chengdu Shaocheng. Chengdu: Southwest Jiaotong University.

Zhang, L. (2019b). Research on Space Reuse of Traditional Public Buildings in Villages in Mentougou District, Beijing. Beijing: Beijing University of Architecture and Architecture.

Zhao, L. (2019a). Research on the Recycling and Utilization of Traditional Village Buildings in the Suburbs of Beijing. Beijing: Beijing Forestry University.

Zhao, M. Z. (2019b). Research on Commercial Building Renovation Based on Function Conversion. Dalian: Dalian University of Technology. 
Zhu, K. (2013). The Organic Renewal of the Architectural Space under the Appeal of the Persistence of the Folk Culture of the Village in the City. Guangzhou: South China University of Technology.

Zhu, Z. J., \& Yang, J. H. (2016). Research on the Protection and Development of the Authenticity of Traditional Villages-Taking Wushiyan Embankment in Luotian, Hubei Province as an Example. Garden Gardens, 11, 68-72. 